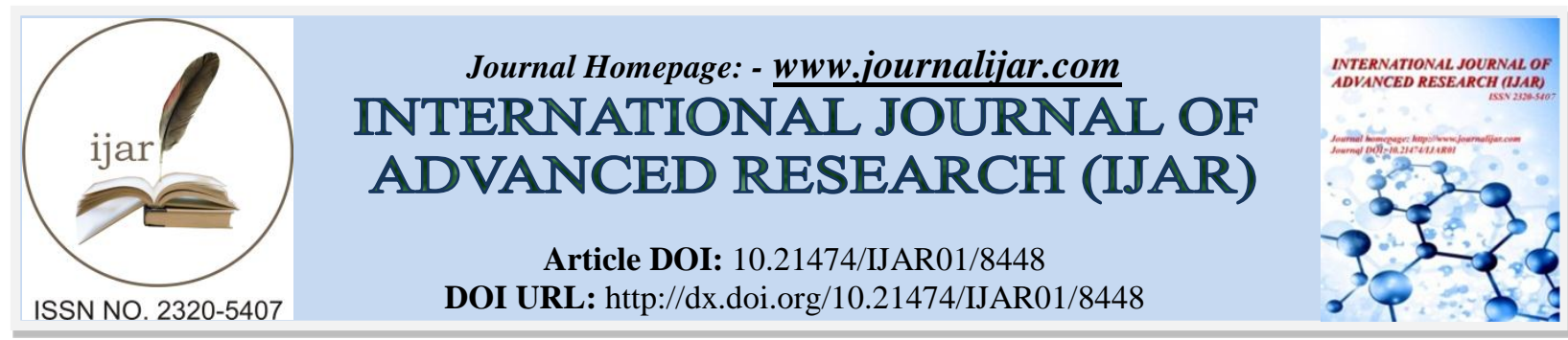

RESEARCH ARTICLE

\title{
THE PRIMARY ABDOMINAL BLAST IN THE BURNED: THE EMERGENCY THAT CAN GO UNNOTICED.
}

\author{
Mariam Quaboul $^{1}$, Abdolkodous Bhihi ${ }^{1}$, Mehdi Mehrouch ${ }^{1}$, Imane Yafi ${ }^{1}$,Moulay Driss El Amrani ${ }^{1}$, Yassine \\ Benchamkha $^{1}$, Hayate Bouchtalla $^{2}$ and Said Younous ${ }^{1}$. \\ 1. Aesthetic Plastic Surgery Service and Burns, Mohammed VI University Hospital - Cadi Ayyad University - \\ Marrakech, Morocco. \\ 2. Pediatric intensive care unit - Mother-Child Hospital - Mohammed VI University Hospital - Cadi Ayyad \\ University - Marrakech, Morocco.
}

\section{Manuscript Info}

Manuscript History

Received: 20 November 2018

Final Accepted: 22 December 2018

Published: January 2019

Key words:-

burn; primary blast, abdomen.

\section{Abstract}

Blast lesions are considered complex and dangerous in the face of lifethreatening and functional consequences. The difficulty of taking care of these patients calls for an exhaustive diagnostic procedure and imposing urgent medico-surgical decisions. We report a case of abdominal blast following a gas cylinder explosion where the mechanism and seat of the lesion remain exceptional.

Copy Right, IJAR, 2018,. All rights reserved.

\section{Introduction:-}

Abdominal blast lesions are scarce, calling for renewed interest in the face of the increase of terrorist acts, domestic gas explosions and industrial accidents. All physicians must be involved and should know how to touch upon blast injury. An explosion in a closed environment causes major lesions including extensive burns, an inhalation syndrome along with other associated trauma. Burning in this context can be direct by scalding or contact but also by blast effect. The topography of the blast lesions is related to the mechanism, the closed environment, the position of the victim and his/her situation in relation to the epicenter.

\section{Observation:-}

We report the case of a 72-year-old patient (1 meter $81,87 \mathrm{~kg}$ ) [Figure 1], with a history of high blood pressure, a victim of a domestic accident related to the explosion of a gas cylinder in a closed environment causing him an initial loss of consciousness associated with burning. The patient was admitted at $\mathrm{H}$ (hour) 2 of the incident, after being conditioned during the medical transfer (two venous routes, oxygen therapy ...). On arrival at the emergency department of Mohammed VI University Hospital, an already notified medical team made up of plastic surgeons and resuscitators examined and evaluated the patient. We found a hemodynamically stable polypnemic patient with a Glasgow score of 15; the ophthalmologic examination was featureless, the tympanoscopy was normal, a wound of the right hand of two superficial centimeter without tendinous lesions or other, a second degree burn in intermediate and deep mosaic of a surface of 55\% concerning the face, the neck, the perineum and the four limbs, circular at both forearms. The anterior and posterior trunk was uninjured, but the abdomen had spread abdominal pain with no particular character. The patient was installed in the decoiling room in front of the suspicion of inhalation syndrome or even a carbon monoxide poisoning and the high lease score higher than 100. The patient benefitted from a central way triple track light monitoring and a urinary survey. Vascular filling was undertaken according to the Evens formula in addition to analgesia and anti-tetanus vaccination. A radiological assessment was performed:

Corresponding Author:-Mariam Quaboul.

Address:-Aesthetic Plastic Surgery Service and Burns, Mohammed VI University Hospital - Cadi

Ayyad University - Marrakech, Morocco. 
cerebral CT and abdominopelvic CT as well as cardiopulmonary evaluation by cardiac echography and thoracic CT. These examinations showed the presence of a mixed peritoneal effusion of low abundance while the remains of the explorations were normal [Figure 2]. In parallel a complete biological assessment and a surveillance of the different clinical and biological parameters were carried out. In front of the suspicion of intestinal perforation by primary Blast, the decision of escarrotomy of both forearms with abdominal exploration was arranged . The patient found himself at the block at $\mathrm{H} 4$ of the burn where he benefited from discharge incision with an occlusive dressing with silver sulfadiazine. The exploratory laparotomy revealed a contusion involving the sub-totality of the hail circumference and measuring $2.5 \mathrm{~cm}$ in width associated with an adjacent perforation, an ostomy resection was performed with simple sequences requiring fasting(empty stomach) and an echo-scano graphic control. . The patient was transferred to a ventilated, intubated and sedated resuscitation. He was put under triple antibiotic therapy (Clavulanic acid amoxicillin plus Ciprofloxacin and Metronidazole) and a gastric protection with parenteral nutrition.

At the $48 \mathrm{~h}$ of his admission the patient presented a general state deterioration, an oliguria at $0.3 \mathrm{cc} / \mathrm{kg} / \mathrm{h}$ with hypotension requiring drastic resuscitation measures, filling with albumin and Ringer lactate and broad spectrum antibiotic therapy .

After 4 hours of intensive medication with the introduction of epinephrine and norepinephrine through the electric syringe pump and a biological assessment which objectified a rise in CRP $(230 \mathrm{mg} / 1)$ procalcitonin $0.96 \mathrm{ng} / \mathrm{ml}$, an organic renal failure hydroelectrolytic disorders (hyper kalemia: $5.9 \mathrm{mmol} / \mathrm{l}$, natremia: $149 \mathrm{mmol} / \mathrm{l}$ ) hyperglycemia and hypoalbuminemia the patient died at the $53 \mathrm{~h}$ of his admission of vasoplegic shock probably of septic origin .

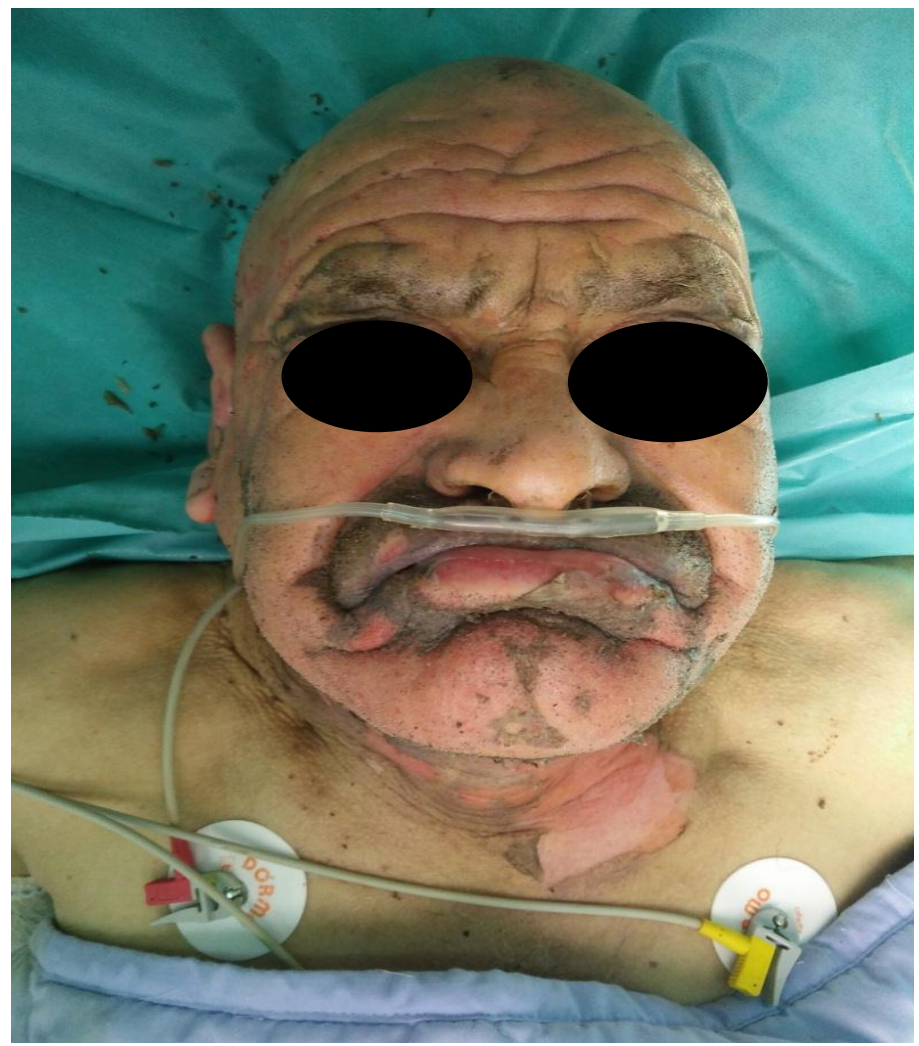

Figure 1:-72-year-old patient, appearance at admission to $\mathrm{H} 2$ of a gas cylinder explosion in a closed environment. 2nd degree facial, nostrils, eyebrow and lips burn 


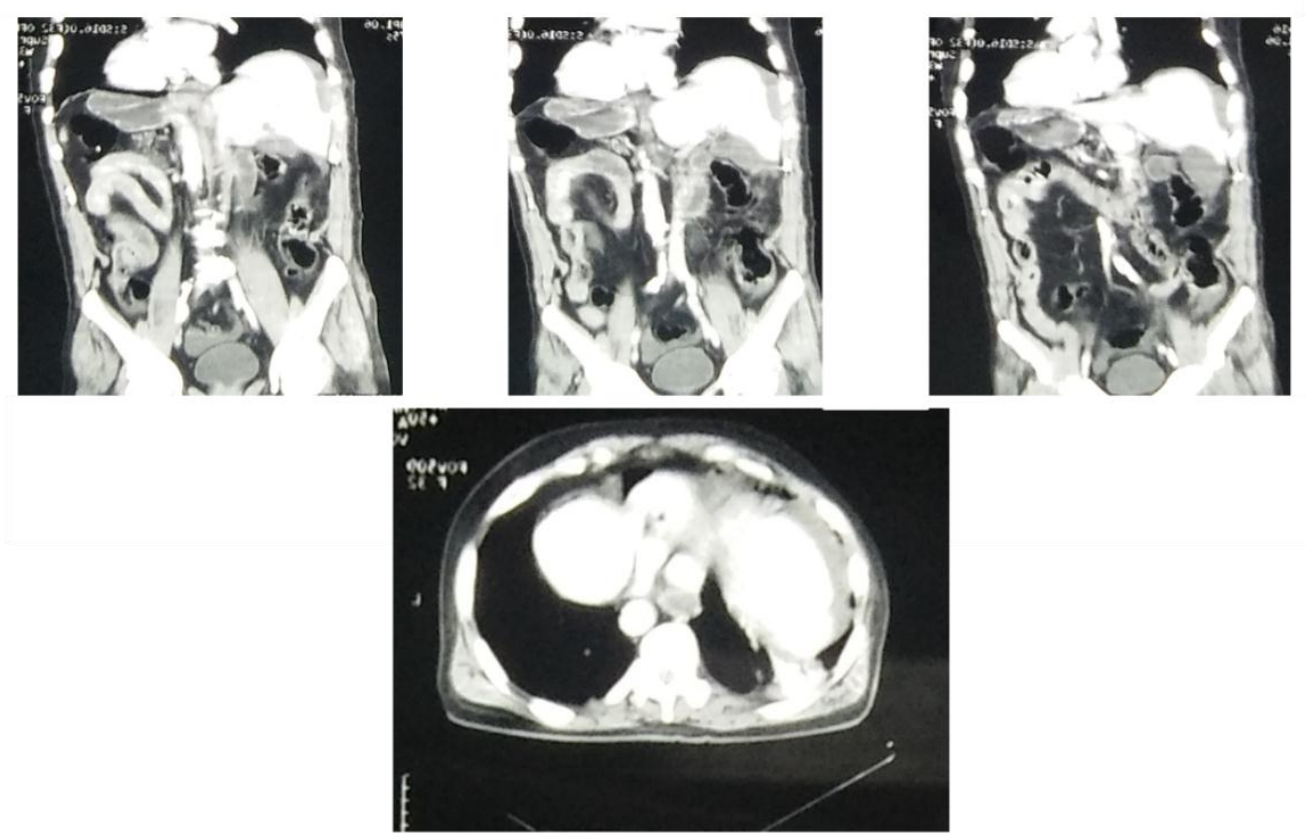

Figure 2: Epanchement péritonéal mixte: bulles pneumopéritoine en sus hépatique+ épanchement de faible abondance péri hépatique, en inter anse et à l'étage pelvien. II s'y associe une infiltration diffuse de la graisse mésentérique.

Figure 2:-Mixed peritoneal effusion : pneumoperitoneum bubbles in addition to hepatic plus effusion of low perihepatic abundance, inter cove and on pelvic floor. It is associated with an expanded infiltration of mesenteric fat.

\section{Discussion:-}

The abdominal blast is defined as the involvement of one or more organs of the abdominal cavity following the effects of a shock wave resulting from an explosion. The first description was done in 1941 by O'Reilly JN and Gloyne SR who diagnosed it in 5 survivors (out of 17) of an air explosion. Four of these patients died from damage to the digestive tract (haemorrhage and perforation) [1]. This type of lesion has been found in different circumstances and by several mechanisms (or explosion of a bomb or gas cylinder in an open, enclosed, aerial or submarine environment..) [2,3]. An explosion is an exothermic chemical reaction that is accompanied by a sudden and significant release of energy in the form of high-pressure, high-temperature gas production, with schematically three components: the shock wave (blast wave ), the breath and the heat. Explosions can be the result of domestic or industrial accidents but are now often the result of acts of terrorism or war, with blast lesions causing severe physical and psychological damage. The lesions caused by the explosion are divided into four categories : The primary lesions are related to the shock wave and are called "blast lesions" or improperly "blast". They mainly concern gaseous organs (eardrums, lungs and digestive tract) but can affect solid organs (liver, spleen, brains, bones, heart ...). Secondary lesions are projectile ones (debris from the projectile or the environment). They cause unusual penetrating trauma (screening) in peacetime in France. Tertiary lesions are the consequence of the projection of the victim herself onto the environment. These are usually closed trauma, comparable to those of classical trauma. The other lesions (burns, crushing, psychic trauma, smoke poisoning), sometimes called quaternary lesions, are not, strictly speaking, explosive or even abnormal lesions defined by inflammatory conditions [4]. The physiopathology of the shock wave : When it encounters an obstacle, it is partly transmitted or coupled to the new material (depending on its acoustic impedance) and partly reflected. In the new environment, the energy propagates in the form of shock waves (stress waves) causing a significant acceleration without large displacement of the organs, preferably affecting the hail and in the form of shear waves (shear waves) with a weaker acceleration but a large displacement, rather injuring the colon. The lesional mechanisms are of different nature (compression relaxation, parietal stress, spraying) (5-6-7). The lung and digestive tract are damaged for nearpressure levels but the colon seems more sensitive than hail (8). Blast lesions usually involve the victims closest to the epicenter of the blast. They are always projected, carrying screening lesions and sometimes burned or amputated. Dizziness, tinnitus or 
deafness are associated with the tympanic blast. Tympanoscopy should be systematic, looking for tympanic perforation or hemotympanum. The diagnosis is usually under clinical examination, the patient describes abdominal pain or other digestive signs (nausea, vomiting, tenesmus, testicular pain, craving). On clinical examination there are signs of perforation which are often masked by the pain of burning or amputation or even an unconscious patient. The tympanum is the most sensitive organ to blast. Although a normal otoscopic examination does not eliminate abdominal or other damage, several teams place otoscopy as one of the criteria for estimating the severity of the blast [9-]. 10]. First-line abdominal ultrasound is used to identify fluid effusions and pneumoperitoin [11]. Associated or not a radiograph of the abdomen without preparation is needed in search of a gassy crescent. These simple and reproducible examinations allow a diagnostic and therapeutic orientation, especially in a disaster situation where the radiology center is full of emergencies while the CT scanner finds its place to detect pneumoperitoneum or peritoneal effusion. Once the blast is recognized, the patient should be left on an empty stomach for signs of worsening by clinical or radiological monitoring. Management or care is surgical, identical to that of digestive perforations of other etiologies. It is the same for antibiotic prophylaxis (choice of the molecule and duration of administration) [12]. In this observation, it was the clinical examination that led us to search for a blast. Radiological examinations were of paramount importance for the therapeutic decision while the tympanoscopy was normal. The difficulty of management was mainly related to the associated lesions (burns), the ground and the advanced age.

\section{Coclusion:-}

The abdominal blast is probably underestimated because it is often associated with major lesions. Early diagnosis is necessary in view of the severity of the lesions and the quality of care that depends on them. Ultrasound and abdominal CT have a major contribution to the identification of lesions but should not delay the medical-surgical treatment that requires a multidisciplinary trained team .

\section{Références:-}

1. O'Reilly JN, Gloyne SR. Blast injury of the lungs. Lancet $1941: 423-8$.

2. Huller T, Bazini Y. Blast injuries of the chest and abdomen. Arch Surg $1970 ; 100$ : 24-30.

3. Katz E, Ofek B, Adler J, et al. Primary blast injury after a bomb explosion in a civilian bus. Ann Surg 1989 ; 209 : 484-8.

4. S. Siah, A. Emane, M. Bertin-Maghit. Blast pulmonaire primaire chez le brûlé. a propos d'un cas et revue de la littérature. Ann Burns Fire Disasters.2016 sep 30 ; 29 ( 3 ) : 189-191.

5. Cripps NP, Cooper GJ. The influence of personal blast protection on the distribution and severity of primary blast gut injury. J Trauma 1996 ; 40 (3 Suppl) : S206-11.

6. Cripps NP, Glover MA, Guy RJ. The pathophysiology of primary blast injury and its implications for treatment. Part II : The auditory structures and abdomen. J R Nav Med Serv 1999 ; 85 (1) : 13-24.

7. Axelsson H, Yelverton JT. Chest wall velocity as a predictor of nonauditory blast injury in a complex wave environment. J Trauma 1996 ; 40 (3 Suppl) : S31-7.

8. Mayorga MA. The pathology of primary blast overpressure injury. Toxicology $1997 ; 121$ (1) : 17-28.

9. Cudennec YF. Carli P, Riou B «Urgences médicochirurgicales de l'adulte ». Arnette ed,; Paris: 1991. Blast; pp. 688-698.

10. Wightman J, Gladish S. Explosions and blast injuries. Ann Emerg Med. 2001;37:664-678.

11. Jones R. Recognition of pneumoperitoneum using bedside ultrasound in critically ill patients presenting with acute abdominal pain. Am J Emerg Med 2007 ; 25 : 838-41.

12. Turégano-Fuentes F1, Pérez-Diaz D2, Sanz-Sánchez M3, Alfici R4, Ashkenazi I5.Abdominal blast injuries: different patterns, severity, management, and prognosis according to the main mechanism of injury. Eur $\mathrm{J}$ Trauma Emerg Surg. 2014 Aug;40(4):451-60. 